\title{
Client Evaluations of WIN and CETA Programs in Arkansas
}

\author{
JANE MCBRIDE GATES
}

Arkansas State University

Public policy analysis has become a major area of interest to political scientists. The government's attempts to create jobs has become an important activity.

The purpose of this study is to examine two public service employment programs, the Work Incentive Program (WIN) and the Comprehensive Employment Training Act Program (CETA), as they are administered on the local level. The CETA program was designed to provide training, employment, and other services leading to unsubsidized employment for economically and educationally disadvantaged persons. The WIN program was established with the objective of training employable recipients of AFDC for jobs.

These two programs were chosen because, first, they seek the solution to one of the most crucial problems in the economy, $i . e .$, the reduction of the high number of unemployed in the work force. Second, the creation of the CETA program in 1973 and the change in the direction of the WIN program in 1968 provide an adequate time perspective to find out how clients evaluate these programs. Third, the objectives of the programs make them suitable for comparison.

\section{Sample}

Ideally, probability sampling is best for generalizing the results from a sample to the universe. However, since the conditions of probability sampling in choice of the research locations could not be met, a purposive sample is used.l Three sites of CETA and WIN programs were selected

Note: The Arkansas Employment Security Division of Research and Statistics is acknowledged for assistance in mailing and other costs of this research.

Fred N. Kerlinger describes purposive sampling as a nonprobability sampling form, "characterized by the use of judgment and a deliberate effort to obtain representative samples by including presumably typical areas of groups in the sample." 
as a purposive sample of all prime sponsorships in Northeast Arkansas. The criteria used were accessibility of data, ethnic mix of population when possible and willingness of participants and agencies to cooperate. The three sites, location of area CETA offices, administered programs in seven counties in Northeast Arkansas: Clay, Craighead, Greene, Lawrence, Mississippi, Poinsett, and Randolph. Northeast Arkansas is predominantly rural. The small towns depend heavily on agriculturally related businesses and industries and the larger cities serve as centers of trade, manufacturing, finance, communications and transportation.

The research data were based on a non-random sample of $277^{\circ}$ responses out of 500 participants surveyed. Of the 500 participants included in the sample, 300 were participants in the Comprehensive Employment Training Agency program and 200 in the Work Incentive Program. The differences in the sample sizes of the individual programs reflect the estimated proportional sizes of the programs statewide in Arkansas.

The 500 participants were randomly selected by the Arkansas Research and Statistics computer services from the total population of 800 CETA and WIN participants in Northeast Arkansas in the 1978-79 fiscal year. The subjects came from urban and rural areas where $56 \%$ of the area's workers are employed in service producing industries, i.e., transportation, communications, public utilities; wholesale and retail trade, finance, insurance and real estate, public administration; and $44 \%$ of the area's workers are employed in goods producing, i.e., agriculture, forestry, construction and manufacturing (Research and Statistics Sections of Arkansas Employment Security Division, 1977). Thus, subjects coming from similar backgrounds in both programs established some degree of homogeneity in the research. All subjects were mailed questionnaires in March, 1980. By the end of May, 1980,277 (56\%) questionnaires had been returned.2

2 This return rate compares favorably with other major studies which have relied on mailed questionnaires. 
The mailed questionnaire, composed of thirty-five closed-ended questions and seven open-ended questions was sent to the 500 subjects in the study who had been terminated in the WIN and CETA programs during 1978-79. The 500 questionnaires were mailed to the subjects by the Arkansas Employment Security Division Research and Statistics Department. A self-addressed, stamped envelope was enclosed with the researcher's name and address on it. This precaution was taken in an effort to eliminate any inhibitions respondents may have had in answering the questions asked in the questionnaire. The names and addresses of the respondents remained anonymous to the researcher. Each questionnaire was assigned a number which coincided with a number assigned to the subject by the ESD Research and Statistics Department once computer printout names and addresses were available. Follow-up letters were mailed out four weeks after the questionnaire mailing when less than 25\% of the subjects had responded. By the end of May, 1980,277 (56\%) questionnaires had been returned. Of the 223 non-respondents a follow-up check by telephone by the ESD Research and Statistics Department showed that 168 had moved from addresses given to the agencies and that present addresses were unknown.

A variation of the Likert Method, that of eliminating the "undecided" or "neutral" category, thus forcing respondents to choose between favorable and unfavorable stances was chosen for the thirty-five closed-ended questions (Oskamp, 1977:37-39). A simple "yes" "no" format was used for some of the questions as well as open-ended questions allowing subjects to include information he feels not previously addressed.

\section{Data Analysis and Findings}

This study uses two principal ways of addressing program effectiveness. First, a descriptive approach is used, simply comparing the CETA and WIN participants' responses about program performance, whether or not they found jobs, and the characteristics of the clientele served in each program. Second, an explanatory approach is used examining what factors are related, potentially in causal manner, to the differences in the participants' attitudes in causal manner, to the differences in the participants' attitudes toward the CETA and WIN programs and to their success rate in obtaining employment. 


\section{A Comparative Analysis of the Characteristics of CETA and WIN Participants}

In this part of the study data detailing the socioeconomic backgrounds of the CETA and WIN participants will be presented (Table 1). These characteristics are important indicators of the client groups being served by the two programs. They are also important indicators of whether the programs are meeting the objectives for which they were designed. The "typical" (i.e., modal) CETA subject in the study tended to be male (52\%), under 29 (61\%), with less than a twelfth grade education (53\%), predominantly white (79\%), married (52\%), a rural resident (69\%), and almost half were economically disadvantaged--with $48 \%$ having an annual family income less than $\$ 5,500$ and $52 \%$ with an annual family income of $\$ 5,500$ or more.

The typical WIN subject in the study tended to be female (94\%), under 29 (51\%), with less than a twelfth grade education ( $72 \%$ ), slightly over half of the respondents were black (54\%), with more separated, divorced or widowed (39\%), and rural residents (59\%). The WIN program was almost entirely composed of the economically disadvantaged with only $13 \%$ having an annual family income of $\$ 5,500$ or more.

Overall, the characteristics of participants in both the CETA and WIN programs are somewhat similar with regard to age, education and place of residence. Table 1 shows the overall distribution of demographic variables in the study; there are significant differences between the characteristics of the participants of the two programs. In the CETA program there were more male participants (52\%), whereas in the WIN program just the opposite is true, 95\% females. The CETA program was composed predominantly of whites (79\%) while the WIN participants were slightly more than half black (54\%). Among CETA participants $48 \%$ had family incomes of less than $\$ 5,500$. Among WIN participants $87 \%$ were from families with income of less than $\$ 5,500$. It was expected originally that there would be more WIN participants than CETA participants whose family incomes were $\$ 5,500$ or less annually and that WIN would have more black and female clients, primarily because WIN is the only program which serves welfare recipients exclusively. We can see those expectations borne out in these results. Thus, we can conclude that the WIN program is more specifically targeted to the economically disadvantaged than is the CETA program, which was the intent of the WIN program. 
Table 1. Percentage Distribution of Participants in CETA and WIN Survey 1980 .

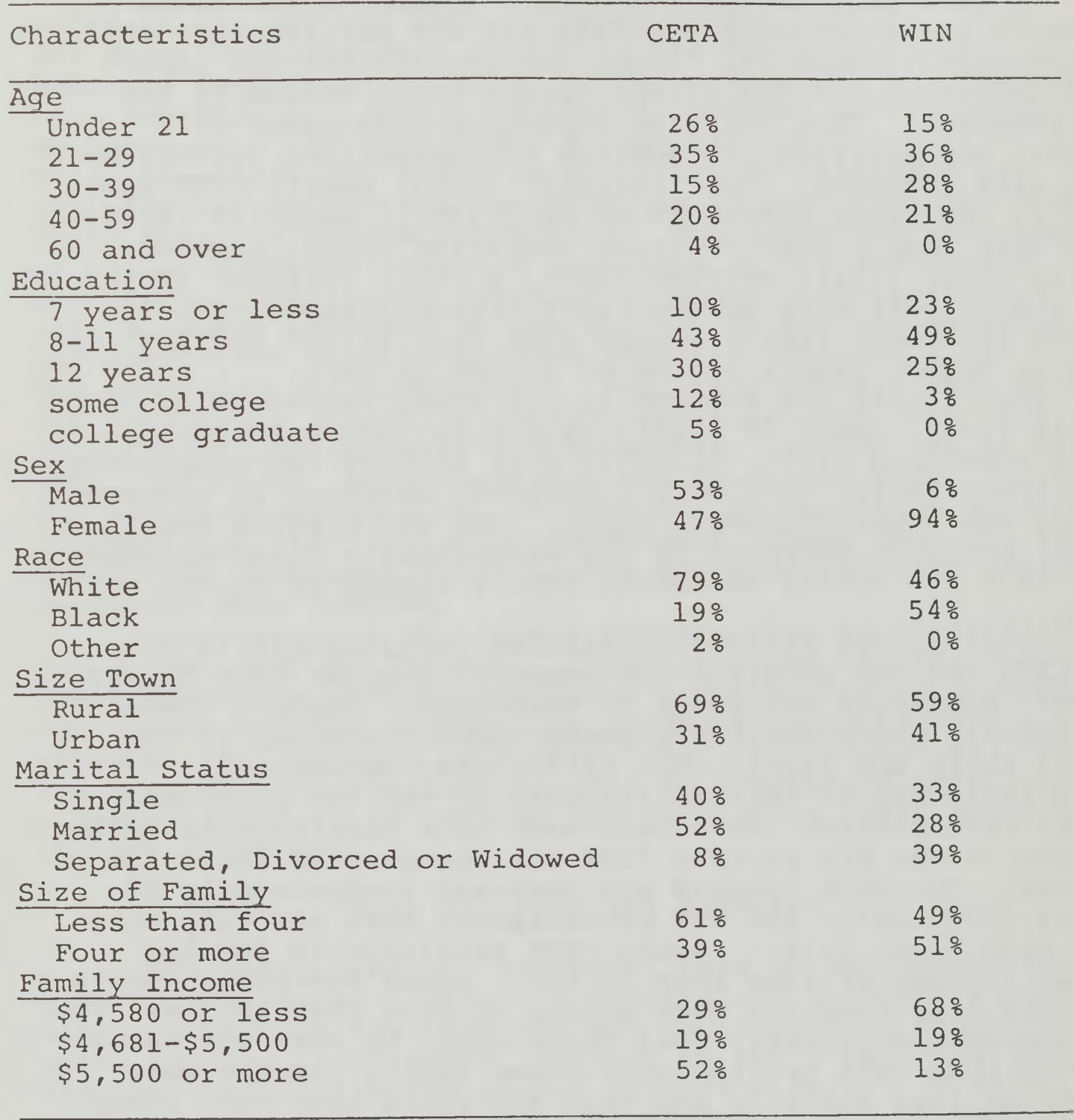

Rural = population of 9,999 or less

Urban = population of 10,000 or more 
The characteristics of participants in the CETA program in Northeast Arkansas are similar to those found among CETA praticipants on the national and state levels. Generally, participants were more apt to be males than females in the prime working years of 22 to 44 , to be better educated and to be less likely to be members of minority groups. Fewer than half of the CETA participants were likely to be disadvantaged (Research and Statistics Section of Arkansas ESD, 1979:59).

When a comparison of the characteristics of CETA and WIN participants nationwide, statewide and in Northeast Arkansas was made, several major findings were emerged:

(1) CETA participants in this study were more often male nationally than in Arkansas and in Northeast Arkansas.

(2) CETA participants were more often white nationally than in Arkansas, particularly in Northeast Arkansas.

(3) CETA participants tended to be more economically disadvantaged nationally than in Arkansas and in Northeast Arkansas.

(4) WIN participants were more often female and black in Arkansas and Northeast Arkansas than in the nation as a whole and more often than in the CETA program.

(5) WIN participants were more often economically disadvantaged in Northeast Arkansas and Arkansas than in the nation as a whole.

Thus, the comparison of CETA and WIN characteristics with those found nationwide and statewide in previous studies serve as an informal external check on the validity of the data (socioeconomic characteristics of clients served in the programs) presented in this research (Campbell and Stanley, 1963:17).

Charles Goodsell concludes that "...if a program serves primarily youths or blacks... we would anticipate a relatively unfavorable evaluation of the program" (1980:12336). Therefore, I expect that WIN clients will be more critical toward that program and have lower job placement success than the CETA program because WIN contains a higher proportion of blacks and young females.

\section{A Comparison of CETA and WIN Participants'} Perceptions of Program Performance

This part of the study employs the descriptive approach to show how subjects feel about the programs they participated in during fiscal years 1978-1979. In this first 
section we will look at questions relevant to staff handling of cases. Few studies have been done where former participants in WIN and CETA programs relate their feelings about and perceptions of their first and subsequent bureaucratic encounters with each agency.

A voluntary versus a compulsory entrance in the program should affect the clients' attitudes. Blau and scott found that the organizational structure of programs affect significantly the nature of the encounter as well as the client's attitude toward the program. I would anticipate then, that CETA clients should respond more favorably toward the staff because of the voluntary procedure operational in that program's organizational structure while WIN clients more unfavorably toward staff because of the WIN program's referral entrance procedure (Blau and scott, 1962:76-77).

\section{Attitudes Toward Staff}

In the CETA program $94 \%$ of the subjects agreed or strongly agreed that CETA staff employees were always courteous. Eighty-nine percent agreed or strongly agreed with the statement that the employees were willing to talk. Eighty-two percent disagreed or strongly disagreed that they had to wait too long before seeing the staff employee assigned his case. Eighty-five percent agreed or strongly agreed with the proposition that the employees showed a low of interest in them. When asked if it took too long for them to get into the program, $85 \%$ disagreed or strongly disagreed. When asked if the staff were generally helpful to them, 91\% agreed or strongly agreed. When asked if the staff showed a lack of interest in them, $77 \%$ disagreed or strongly disagreed. When asked if the staff showed a lack of interest in them, $77 \%$ disagreed or strongly disagreed. When asked about accessibility to the office, $80 \%$ agreed or strongly agreed that the office was easy to get to. Table 2 shows participants' feelings toward the staff. CETA participants felt most positive about the staff's willingness to talk to them. Clients tended to be most critical of the amount of time it took for them to get into the program. However, in general, these results indicate a very positive evaluation of the CETA staff encounter by these former participants. 
In the WIN program, 888 of the participants strongly agreed or agreed that WIN staff employees were always courteous. Ninety-four percent strongly agreed or agreed that they were always willing to talk. Eighty-three percent strongly disagreed or disagreed that they had to wait too long to see the staff employee assigned his or her case. Eighty-eight percent strongly agreed or agreed that the employee showed a lot of interest in them. When asked if it took too long for them to get into the program, 85\% strongly disagreed or disagreed. When asked if the staff were generally helpful, $89 \%$ strongly agreed or agreed. When asked if the staff showed a lack of interest in them, 73\% strongly disagreed or disagreed. Fifty-one percent responded that the WIN office was easy to get to. Table 2 shows the percentage distribution of CETA and WIN participants' feelings toward staff encounters.

These results indicate that both CETA and WIN clients perceived their encounter with the staff of these programs quite favorably. Clients responded most positive about the staff's willingness to talk to them and courteous treatment. Clients tended to be most negative about the amount of time waiting in the office and lack of interest of employees in these programs.

\section{Attitudes Toward Training}

Training has been one of the controversial areas in the CETA program. The "leaf raking" or "make work" argument has been used constantly to discourage funding of PSE programs. For this reason the study included several items on training. The results of those items are reported in Table 3. When asked if they were satisfied with the quality of training received in the program, $76 \%$ of the CETA participants agreed or strongly agreed that they were satisfied. Eighty-four percent of subjects agreed or strongly agreed that they felt they had a better chance to get a job because of their experience in the CETA program. Seventy-eight percent agreed or strongly agreed that the program provided good participation for a job. Seventy-five percent of the participants felt that it was the agency's responsibility to get them jobs while $25 \%$ disagreed. Fifty-four percent agreed or strongly agreed that they felt the program would lead them to higher level job opportunities.

A major objective of the WIN program is to get persons off the AFDC payroll and into the labor force. Therefore, the training and job preparation aspects of the WIN program are of crucial importance to the clients individually and 
Table 2. Percentage Distribution of CETA and WIN Participants Response Toward Encounter With Agency Staff

\begin{tabular}{|c|c|c|c|c|c|c|c|c|}
\hline \multirow[t]{2}{*}{ Variables } & \multicolumn{2}{|c|}{$\begin{array}{l}\text { Strongly } \\
\text { Aqree }(\%)\end{array}$} & \multicolumn{2}{|c|}{$\begin{array}{l}\text { Agree } \\
(8) \\
\end{array}$} & \multicolumn{2}{|c|}{$\begin{array}{c}\text { Disagree } \\
(\%) \\
\end{array}$} & \multicolumn{2}{|c|}{$\begin{array}{l}\text { Strongly } \\
\text { Disagree }\end{array}$} \\
\hline & CETA & WIN & CETA & WIN & CETA & WIN & CETA & WIN \\
\hline courteous & 29 & 29 & 65 & 59 & 5 & 9 & 1 & 3 \\
\hline willing to talk & 28 & 30 & 61 & 64 & 9 & 4 & 2 & 2 \\
\hline $\begin{array}{l}\text { *wait too long } \\
\text { showed lot of }\end{array}$ & 6 & 5 & 12 & 12 & 64 & 63 & 18 & 20 \\
\hline interest & 23 & 30 & 62 & 58 & 10 & 7 & 5 & 5 \\
\hline *too long to & & & & & & & & \\
\hline get in program & 10 & 6 & 5 & 9 & 63 & 60 & 22 & 25 \\
\hline $\begin{array}{l}\text { staff helpful } \\
\text { * showed lack }\end{array}$ & 23 & 23 & 68 & 66 & 6 & 6 & 3 & 5 \\
\hline $\begin{array}{l}\text { of interest } \\
\text { office easy to }\end{array}$ & 8 & 12 & 15 & 15 & 61 & 53 & 16 & 20 \\
\hline get to & 19 & 38 & 59 & 13 & 16 & 34 & 6 & 16 \\
\hline
\end{tabular}

Note: Subjects' responses to twenty-one questions asked in the questionnaire are examined. A modified Likert Scale is used; subjects were asked to indicate how they felt about the statement made about the program by checking the following responses: Strongl agree, disagree, or strongly disagree. 
to society as a whole. When WIN clients were asked if they were satisfied with the quality of training received in the program, 59\% of the WIN participants agreed or strongly agreed that they were satisfied (Table 3). Eighty-seven percent of subjects agreed or strongly agreed that they felt they had a better chance to get a job because of their experience in the WIN program. Ninety-six percent agreed or strongly agreed that the program provided good preparation for a job. Eighty-five percent of WIN participants felt that it was the agency's responsibility to get them jobs while only 15\% disagreed. Sixty-one percent agreed or strongly agreed that they felt that participation in the program would lead them to higher level job opportunities. Generally speaking, WIN participants were not more critical of their training received in the program than were CETA participants. CETA participants felt most positive about their improved chances of getting a job because of their CETA training while WIN participants felt most positive about the program providing good preparation for a job. Both CETA and WIN clients tended to be most negative about these programs helping them to get a job once training had been completed. This assessment is probably realistic given that the CETA and WIN programs can help train people for jobs but the programs cannot ultimately guarantee them jobs in the private sector upon termination.

\section{Jobs Found}

As stated in the outset of this study one of the most critical issues relating to public service employment clientele in the United states is the number actually getting jobs after completion of their training in these programs. In other words, are these programs working with respect to that central objective? Fifty-three percent of former CETA participants surveyed found jobs. Forty-one percent of the 53\% of former CETA participants who found jobs they were trained for upon completion of the program. Therefore, only $12 \%$ of former CETA participants who found jobs were unable to find the type of job they were trained for in the program. Another 47\% said they did not find jobs at all. Forty-eight percent of CETA participants said they did not find jobs at all. Forty-eight percent of CETA participants said that they learned a skill while $49 \%$ said that they did not learn a skill at all. Yet, fifty-three percent of the CETA participants encouraged others to participate in the program. The strongest criticism of 
Table 3. Percentage Distribution of CETA and WIN Participants' Response Toward Training Received

\begin{tabular}{|c|c|c|c|c|c|c|c|c|}
\hline \multirow[t]{2}{*}{ Variables } & \multicolumn{2}{|c|}{$\begin{array}{l}\text { Strongly } \\
\text { Agree } \\
(8)\end{array}$} & \multicolumn{2}{|c|}{$\begin{array}{c}\text { Agree } \\
(\%)\end{array}$} & \multicolumn{2}{|c|}{$\begin{array}{c}\text { Disagree } \\
\left(\frac{\circ}{0}\right)\end{array}$} & \multicolumn{2}{|c|}{$\begin{array}{l}\text { Strongly } \\
\text { Disagree } \\
\qquad(8)\end{array}$} \\
\hline & CETA & WIN & CETA & WIN & CETA & WIN & CETA & WIN \\
\hline chances better & 28 & 27 & 56 & 60 & 13 & 23 & 3 & 0 \\
\hline $\begin{array}{l}\text { good prepara- } \\
\text { tion } \\
\text { satisfied with }\end{array}$ & 18 & 27 & 60 & 69 & 17 & 14 & 5 & 0 \\
\hline $\begin{array}{l}\text { quality of } \\
\text { training } \\
\text { agency's respon }\end{array}$ & 21 & 12 & 55 & 47 & 20 & 31 & 4 & 10 \\
\hline $\begin{array}{l}\text { sibility } \\
\text { higher level jo } \\
\text { opportuni- }\end{array}$ & 19 & 28 & 56 & 57 & 21 & 14 & 4 & 1 \\
\hline ties & 17 & 22 & 37 & 39 & 39 & 31 & 7 & 8 \\
\hline helped get job & 16 & 13 & 33 & 42 & 42 & 38 & 9 & 7 \\
\hline
\end{tabular}

Table 4. Percentage Distribution of CETA and WIN Participants' Response Toward Training Received and Jobs Found

Variables

Yes

No

$(8)$

( 8 )

\begin{tabular}{lcccc}
\hline & CETA & WIN & CETA & WIN \\
found job & 53 & 60 & 47 & 40 \\
got job trained for & 41 & 27 & 59 & 73 \\
learned a skill & 51 & 15 & 49 & 85 \\
encouraged others & 53 & 41 & 47 & 49 \\
\hline
\end{tabular}

$\mathrm{N}=177$ 
the CETA program was related to jobs....either the quality of training, preparation for a job, expectations of higher level job opportunities, or assistance provided in getting a job. Table 4 shows clients responses toward training received and jobs found. Generally, these assessments shown in Table 4 are less positive than those of their staff encounters shown above in Table 2 .

Sixty percent of former WIN participants surveyed found jobs. Only twenty-seven percent of the $60 \%$ of former WIN participants who found jobs actually found jobs they were trained for upon completion of the program. Another $40 \%$ said they did not find jobs at all. Only fifteen percent of WIN former participants said that they learned a skill while $85 \%$ said that they did not learn a skill at all. Yet forty-one percent of the WIN participants encouraged others to participate in the program. More CETA participants said that they learned a skill (5l\%) than did WIN participants (15\%). Nevertheless, both CETA and WIN clients' attitudes are rather positive toward training aspects, but they were less sanguine about their job prospects.

\section{Rising of Expectations}

Governmental programs are often criticized as raising the expectations of the participants unrealistically and for promising more than they can deliver and thus leading to disillusionment and alienation. Therefore, the study tapped this area also and the results are synopsized in Table 5. In fact, most of the items reported in Table 5 are variations on the Survey Research Center's classic cynicism scale items. These alienation items are one dimension of the client satisfaction analysis which is an important aspect of this study.

When asked if the respective programs promised more than they could deliver, fifty-one percent of the CETA subjects felt that the program did promise more than it delivered. However, when asked if the program was a waste of their time, $94 \%$ disagreed or strongly disagreed. When asked if the CETA program was one of the best governmental programs available for them, $91 \%$ agreed or strong agreed. When asked if they felt the government wasted a lot of money on the program, $84 \%$ disagreed or strongly disagreed. Table 5 shows participants responses and feelings about the program performance in the general "political cynicism" or mistrust area. 
Table 5. Percentage Distribution of CETA and WIN Participants' Response Toward Program Performance and Expectations

\begin{tabular}{|c|c|c|c|c|c|c|c|c|}
\hline \multirow[t]{2}{*}{ Variables } & \multicolumn{2}{|c|}{$\begin{array}{l}\text { Strongly } \\
\text { Agree ( }\left(\frac{0}{0}\right)\end{array}$} & \multicolumn{2}{|c|}{$\begin{array}{l}\text { Agree } \\
\left(\frac{0}{0}\right)\end{array}$} & \multicolumn{2}{|c|}{$\begin{array}{c}\text { Disagree } \\
(\%)\end{array}$} & \multicolumn{2}{|c|}{$\begin{array}{l}\text { Strongly } \\
\text { Disagree }\end{array}$} \\
\hline & CETA & WIN & CETA & WIN & CETA & WIN & CETA & WIN \\
\hline $\begin{array}{l}\text { promise more } \\
\text { program waste of }\end{array}$ & 14 & 9 & 37 & 42 & 36 & 42 & 4 & 7 \\
\hline $\begin{array}{l}\text { time } \\
\text { one of best govern }\end{array}$ & - & 3 & 5 & 22 & 63 & 50 & 31 & 25 \\
\hline $\begin{array}{l}\text { ment programs } \\
\text { government gener- }\end{array}$ & 28 & 24 & 63 & 61 & 7 & 14 & 2 & 1 \\
\hline ally wastes money & 6 & 6 & 10 & 9 & 54 & 55 & 30 & 30 \\
\hline
\end{tabular}

$\mathrm{N}=177$

Fifty-one percent of WIN participants felt that the program promised more than it delivered while 49\% strongly disagreed or disagreed (Table 5). When asked if the program was a waste of time, $75 \%$ of the subjects strongly disagreed or disagreed. When asked if it were one of the best governmental programs available for them, 85\% strongly agreed or agreed. Eighty-five percent strongly disagreed or disagreed that the government wasted a lot of money on the WIN program. Eoth CETA and WIN participants responded most positive when asked if the program were one of the best government programs available today. Both CETA and WIN clients were most negative when asked if the programs promised more than they delivered. Former participants of CETA and WIN programs did indeed feel that the programs promised more than they delivered.

\section{Summary of CETA and WIN Evaluations}

The data produced by this study show that clients were no more upset toward the WIN program than toward the CETA program. There is little evidence of the expected impact of the eligibility determinations at intake entrance into the programs; the original expectations were that former 
CETA participants would respond more favorably toward the staff and programs than WIN participants because of the differences in their entrance procedures proved not to be supported by the data.

Large percentages of both CETA and WIN participants were satisfied with the training provided in the programs, but significant percentages also failed to get jobs they were trained for and felt that they were promised more than the agency delivered. Although former participants of both CETA and WIN programs failed to get jobs they were trained for, impressive numbers of participants did find jobs. Possibly the training, work orientation period, impact of increase in family earnings and benefits might explain or account for their desire to find work after termination from the programs, even though these jobs were not ones they were trained for while in the program.

Note: Two general statistical techniques were used to explore the variation in attitudes of CETA and WIN participants toward the two programs. They were cross tabulations and measures of association (Gamma, Eta). The cross tabulations produced contingency tables where chi square was used to see if there were any significant differences across the categories of independent variables being employed. Gamma is a symmetrical measure of association which shows the strength of association between ordinal level variables. Eta is an asymmetrical measure of association employed when the independent variable is is nominal and the dependent variable is ordinal, interval or ratio level. It is basically "an indication of how dissimilar the means on the dependent variables are within the categories of the independent variable." The positive or negative relationships shown to exist between the variables by Gamma and Eta are referred to as correlations. 
In this section an attempt is made to offer some explanations for the variations observed in clients' attitudes and job seeking success rates. The measures of client evaluation are considered to be the responses of former participants in the CETA and WIN programs concerning their training, encounters with staff members, whether they got jobs they were trained for, and their overall degree of satisfaction with the program described in the previous section.

The data in this study lend some support to the findings of Katz, Jacob, Goodsell, Handler, and Hollingsworth, etc., on the discussion of client evaluation of their bureaucratic encounters in public service agencies.

Goodsell, Handler and Hollingsworth found that welfare clients are usually satisfied with their bureaucratic encounters, i.e., the "treatment received and the outcome experienced." Herbert Jacob and Daniel Katz found that blacks tended to be less favorable toward their bureaucratic encounters than whites. When the demographic characteristics of the clients in this study and their attitudes toward the CETA and WIN programs were examined, family income emerged as the strongest related independent variable, while others were found to be weakly related in most cases to the former clients' attitudes toward the programs. Family income when correlated with the attitudinal statement that the WIN program was a waste of time yielded a strong relationship (Gamma $=0.33$ ). Former clients whose earnings were $\$ 5,500$ or more tended to disagree with this statement more so than those who were earning $\$ 4,680$ or less. However, even among those earning less than $\$ 5,500$, less than half agreed that the program was a waste of time. In the CETA program family income was correlated with the statement that the program promised more than it delivered (Gamma $=0.21$ ). Those former participants earning $\$ 5,500$ or more tended to agree less than those earning $\$ 4,680$ or less that the CETA program promised more than it delivered. However, as was found among WIN participants, only $40 \%$ of CETA participants earning $\$ 5,500$ or more disagreed that the program promised more than it delivered. Indeed, the amount of money earned 
by former participants was directly related to former clients' attitudes toward the program but did not greatly affect the level of satisfaction. In the CETA program blacks, members of other ethnic groups, those earning less than $\$ 5,500$, and those with 12 years of education and "some college" tended to be the most critical, while in the WIN program those earning less than $\$ 5,500$ tended to be the most critical of the program.

Both Daniel Katz and Charles Goodsell found the age of the client to be the most predictive independent variable tested with respect to client satisfaction of bureaucratic encounters. In both WIN and CETA programs a larger number of older clients found jobs than younger clients (CETA Gamma $=-0.17$, WIN Gamma $=-0.17$ ). In the WIN program more blacks than whites found jobs they were trained for while in the CETA program more whites than blacks found jobs they were trained for (CETA etc. $=0.21$, WIN etc. $=0.29)$. The sex and education of the participants were weak relationships. Among former CETA participants more older clients, males and whites found jobs while among former WIN participants more blacks and clients with eight to eleven years of education found jobs.

Joel Handler, Ellen Hollingsworth and Scott Briar found a passive and grateful attitude on the part of welfare recipients toward their bureaucratic encounters. A majority of former CETA and WIN participants in this study were satisfied with their training received in the programs, perceived their encounters with the agency quite favorable and expressed little dissatisfaction with the program. The most important independent variables which emerged when examing the relationship between respondents who either succeeded or failed to find a job trained for and the participants' attitudes toward the program were as follows: (I) Former participants in the CETA and WIN programs who found jobs they were trained for felt overwhelmingly that the program was not a waste of time while those who failed to find jobs trained for tended to be somewhat more critical of the program but agreed that the program was not a waste of time (CETA Gamma $=0.31$; WIN Gamma $=0.48$ ). participants in both programs, CETA and WIN, who found jobs strongly felt that these programs were among the best government programs available while those who failed to find jobs agreed somewhat less enthusiastically that these programs were among the best available today (CETA Gamma = 0.43 ; WIN Gamma $=9.35)$. (3) Former participants in both 
WIN and CETA programs who failed to find jobs they were trained for felt that the program did indeed promise more than it delivered while those who were able to find jobs they were trained for felt just the opposite (CETA Gamma = 0.14 , WIN Gamma $=0.35$ ).

This "passive and grateful attitude" of former participants was consistently found until the job success rate variable was examined. Sixty percent of the WIN participants found jobs and only 53\% of the CETA participants found jobs. Among former CETA and WIN participants those who found jobs responded favorably toward the programs when asked about their training, staff encounters and overall performance while those former participants failing to find jobs trained for felt just the opposite. Correlations of job success rates with attitudinal questions tapping former CETA and WIN participants' feelings toward the program yielded the following results: (I) Among CETA participants when the success rate variable was correlated with the attitudinal statement, one of the best government programs, Gamma $=0.43$. (2) When the job success rate was correlated with the statement that the program was a waste of time Gamma $=0.31$. (3) Among WIN participants when the job success rate was correlated with the statement that the program was a waste of time Gamma $=0.48$. (4) When the job success rate was correlated with the statement that the program promised more than it delivered Gamma $=0.35$. Not surprisingly, the clients' success in finding a job, then, did have some impact in increasing the likelihood that they would be positive toward the program. CETA participants who failed to find jobs tended to be more critical of the program than former WIN participants who failed to find jobs. Possibly one explanation for the difference found in the attitudes held by former WIN and CETA participants is that CETA participants with higher levels of education entered the program with greater expectations of the program than did WIN participants.

Generally, those former participants in both programs responded quite favorably toward their encounters in the program regardless of whether they found a job they were trained for or not. Very little difference was found to exist between the responses of CETA and WIN participants' feelings toward the training, staff, and program performance. Most former CETA and WIN participants tended to be satisfied with the program, although, in both cases, 
participants felt that the programs promised more than they delivered. In brief there were no significant differences found between the attitudes and perceptions of former CETA participants as compared to those found among WIN participants. A very strong relationship was found between the program variables and clients' attitudes toward the program. However, the expectation that WIN participants would be more unfavorable toward the program than CETA participants because they were compelled to register or lose AFDC eligibility was not supported.

\section{Conclusion}

A moderate amount of empirical literature to date shows that there is some linkage between demographic characteristics of the client and the client's attitude toward his encounters with agencies. Demographic characteristics have been shown to be predictive independent variables in this study as well as in several other studies examining bureaucratic encounters. In an examination of the bureaucratic encounters in the WIN and CETA programs in this study it was expected that blacks would be more critical of their encounters than whites, particularly in light of the extremely high rates of unemployment among minorities today. It was also expected that older clients would be more favorable toward their encounters than younger clients as was found by Katz in his study. Age, race, family income, education, and job success rate were found to be important independent variables in the study. More older clients found jobs than younger clients. More blacks than whites found jobs in the WIN program while more whites than blacks found jobs in the CETA program. The more family income earned the less critical clients were toward the programs.

Generally, most clients were not critically outspoken about the WIN and CETA programs. Most participants' responses were quite favorable toward bureaucratic encounters. Thus, experiences of entering a public service employment program and being trained for a job are perceived by these former participants as rewarding ones regardless of whether a skill was taught leading to full time employment or whether they found a job after completion of the program. Scott Briar points out that, "Most recipients were grateful because of in their own words, 'a little help to tide us over until we can get back on our feet again (Handler and Hollingworth, 1971:9) '". 


\section{References}

Anderson, James E. (1876). Public Policy-Making. New York: Praeger Publishers.

Blau, Peter M. and W. Richard Scott (1962). Formal organizations: Comparative Approach. San Francisco: Chandler.

Campbell, Donald T. and Julian C. Stanley (1963). Experimental and Quasi-Experimental Designs for Research. Chicago: Rand MCNally and Company.

Goodsell, Charles T (1980). "Client Evaluation of Three Welfare Programs," Administration and Society. California: Sage Publishers.

Handler, Joel F. and Ellen Jane Hollingsworth (1971). The "Deserving Poor": A Study of Welfare Administration. New York: Academic Press.

Jacob, Herbert (1972). "Contact with Government Agencies: A Preliminary Analysis of the Distribution of Government Services," Mid-West Journal of Political Science, Vol. 16. Katz, Daniel, Barbara A. Gutek, Robert L. Kahn and Eugenia Barton (1975). Bureaucratic Encounters: A Pilot Study in the Evaluation of Government Services. Ann Arbor: Survey Research Center. 